\title{
ANALISIS KUALITAS PELAYANAN TERHADAP KEPUASAN WAJIB PAJAK PADA KANTOR PELAYANAN PAJAK PRATAMA GIANYAR (KPP GIANYAR)
}

\author{
I Gusti Ayu Puspita Dewi ${ }^{1}$ \\ I Made Santosa ${ }^{2}$ \\ ${ }^{1,2}$ Fakultas Ekonomi Universitas Ngurah Rai, Bali, Indonesia \\ 2email : Gstpuspita@gmail.com
}

\begin{abstract}
ABSTRAK
Tujuan penelitian untuk menganalisis kualitas pelayanan terhadap kepuasan wajib pajak pada Kantor Pelayanan Pajak Pratama Gianyar (KPP Gianyar), maka dengan sampel 100 responden, dilakukan penelitian mengunakan kuesioner. Data yang diperoleh dari hasil penelitian dengan menggunakan kuesioner, dianalisis dengan menggunakan analisis kuantitatif dan kualitatif. Dalam menentukan katagori indeks kepuasan masyarakat maka harus dicari kepuasan maksimum dan minimum. Rentang skor kepuasan masyarakat di dapat adalah $800.000(-800.000)=1.600 .000$, oleh karena tingkat kepuasan diklasifikasikan menjadi 5 (lima), maka interval skor untuk setiap klasifikasi adalah 1.600.000 : $5=320.000$. Berdasarkan pengukuran indek kepuasan total dengan menggunakan rumus skor kualitas jasa dari Fandy Tjiptono, 2008: 100, maka didapat indeks kepuasan wajib pajak pada Kantor Pelayanan Pajak Pratama Gianyar (KPP Gianyar) sebesar 647.292 dimana point terletak antara 480.000 sampai dengan 800.000 yang artinya sangat puas.
\end{abstract}

Kata Kunci : Kualitas Pelayanan, Kepuasan Wajib Pajak, Kantor Pelayanan Wajib Pajak Pratama Gianyar (KPP Gianyar).

\section{ABSTRACT}

The purpose of the study to analyze the quality of service to the satisfaction of the community at the Office Perbekel Pikat Village, then with a sample of 92 respondents, conducted research using questionnaires. Data obtained from the results of research by using questionnaires, analyzed by using quantitative and qualitative analysis. In determining the category of public satisfaction index must be sought maximum and minimum satisfaction. The range of community satisfaction scores in the can is $1,150,000-(-1,150,000)=2,300,000$, because the level of satisfaction is classified into 5 (five), then the score interval for each classification is 2,300,000: $5=460,000$. Based on the measurement of total satisfaction index by using the formula of score of service quality from Fandy Tjiptono, 2008: 100, hence got indices of community satisfaction at Peking Village Office of Pikat equal to 865.258 where point lies between 690.000 until 1,150.000 which means very satisfied.

Keywords: Service Quality, Public Satisfaction, Perbikatel Desa Pikat Office. 


\section{PENDAHULUAN}

Secara umum persepsi pajak merupakan pungutan wajib yang dibayar rakyat untuk negara dan akan digunakan untuk kepentingan pemerintah dan masyarakat umum. Pajak merupakan salah satu sumber dana pemerintah untuk melakukan pembangunan, baik pemerintah pusat maupun pemerintah daerah. Pemungutan pajak dapat dipaksakan karena dilaksanakan berdasarkan undang-undang. Berdasarkan Undang-Undang pasal 1 (UU No. 28 Tahun 2007) tentang pajak, yang dimaksud dalam Undang-Undang ini yaitu pajak adalah kontribusi wajib kepada negara yang terutang oleh orang pribadi atau badan yang bersifat memaksa, dengan tidak mendapatkan imbalan secara langsung dan digunakan untuk keperluan negara bagi kemakmuran rakyat. Seiring dengan meningkatnya kesadaran masyarakat akan pentingnya membayar pajak, maka penyedia jasa dibidang perpajakan dituntut meningkatkan kualitas atau mutu pelayanan yang mampu memberikan kepuasan bagi masyarakat itu sendiri. Salah satu persoalan yang menjadi perhatian dalam perusahaan adalah bagaimana memahami kebutuhan (needs) dan keinginan (wants) dari setiap konsumen. Sehingga hal ini merupakan suatu bentuk tuntunan bagi pihak kantor dalam memahami karakteristik perilaku konsumennya. Salah satu kontribusi wajib kepada negara yang terutang adalah pajak. Kantor Pelayanan Pajak Pratama Gianyar sebagai tempat penelitian merupakan salah satu kantor administrasi pajak di area Gianyar. Kantor Pelayanan Pajak Pratama
Gianyar mempunyai tugas dalam hal pelayanan kepada wajib pajak yang berkaitan dengan pemungutan pajak. Disamping itu kantor pajak mempunyai visi menjadi institusi Penghimpun Penerimaan Negara yang Terbaik demi Menjamin Kedaulatan dan Kemandirian Negara. Peningkatan pelayanan pada kantor pajak dimaksudkan agar tercipta pelayanan yang berkualitas di bidang perpajakan. Saat ini upaya tersebut terus dipupuk dengan cara meningkatkan profesionalisme, memperbaiki dan menyempurnakan sistem administrasi dan memperbaiki perilaku petugas. Dengan demikian sangat dibutuhkan petugas yang benar-benar menguasai bidangnya, memiliki ketrampilan yang memadai, sikap pragmatis sebagai petugas pelayanan dan profesional dalam tugas/pekerjaaan sehingga menimbulkan kepercayaan dari wajib pajak dan rasa puas terhadap pelayanan yang diberikan.

Adapun fasilitas pelayanan yang disediakan oleh Kantor Pelayanan Pajak Pratama Gianyar adalah : Pelaporan SPT Masa, Pembuatan NPWP, Pembuatan No Efin, Helpdesk. Kegiatan pelayanan yang diberikan oleh Kantor Pelayanan Pajak Pratama Gianyar akan mempengaruhi kepuasan para pembayar pajak, yang pada akhirnya akan membuat mereka menjadi pembayar pajak yang baik. Untuk mengetahui kualitas pelayanan yang diberikan oleh Kantor Pelayanan Pajak Pratama Gianyar kepada wajib pajaknya dapat dibuktikan dari dimensi kualitas pelayanan yang meliputi bukti langsung (tangibles), keandalan (reliability), daya tanggap (responsiveness), jaminan 
(assurance) dan empati (emphaty). Konsumen yang dimaksud dalam hal ini adalah mereka yang berstatus sebagai wajib pajak saat melakukan pelaporan pada KPP Pratama Gianyar.

Penilaian kualitas pelayanan bukan didasarkan atas pengakuan atau penilaian dari pemberi pelayanan, tetapi diberikan oleh pelanggan atau pihak yang menerima pelayanan. Tugas pokok Pemerintah pada hakekatnya adalah memberikan pelayanan kepada masyarakat dalam rangka meningkatkan kesejahteraan masyarakat. Demikian pula Kantor Pelayanan Pajak Pratama Gianyar (KPP Gianyar) sebagai penyelenggara pelayanan publik di bidang pajak dan retribusi daerah dalam melayani masyarakat. Dalam hal ini wajib pajak juga tidak terlepas dari beberapa permasalahan seperti yang telah disampaikan diatas. Dari uraian tersebut diatas melatarbelakangi penulis untuk mengetahui Kualitas Pelayanan dalam meningkatkan Kepuasan Wajib Pajak di Kantor Pelayanan Pajak Pratama Gianyar (KPP Gianyar).

Pokok permasalahan penelitian ini berdasarkan latar belakang masalah yang dijelaskan adalah Bagaimanakah kualitas pelayanan terhadap Kepuasan Wajib Pajak pada Kantor Pelayanan Pajak Pratama Gianyar (KPP Gianyar)?

Faktor-faktor pelayanan manakah yang dianggap penting dan dapat memuaskan wajib pajak pada Kantor Pelayanan Pajak Pratama Gianyar (KPP Gianyar)?

\section{METODE PENELITIAN}

Lokasi penelitian dilakukan pada Kantor Pelayanan Pajak Pratama Gianyar (KPP Gianyar) di Jalan By Pass Dharma Giri, Desa Buruan, Kec. Blahbatuh, Kab.Gianyar, yang merupakan salah satu kantor administrasi pajak di area Gianyar. Obyek dalam penelitian ini adalah kualitas pelayanan terhadap kepuasan wajib pajak di Kantor Pelayanan Pajak Pratama Gianyar (KPP Gianyar). Dalam penelitian ini yang menjadi independent variabel adalah kualitas pelayanan (X) terdiri dari : bukti langsung, keandalan, daya tanggap, jaminan, empati, sedangkan yang menjadi dependent variabel adalah tingkat kepuasan wajib pajak (Y). Populasi dalam penelitian ini adalah sebanyak 64.141 orang wajib pajak badan dan pribadi dari data per tahun 2016 terakhir yang terdaftar pada Kantor Pelayanan Pajak Pratama Gianyar. Mengingat keterbatasan waktu, tenaga dan biaya, maka dari keseluruhan populasi masyarakat wajib pajak yang dipilih dalam penelitian ini sebagai sampel adalah sebanyak 100 orang responden. Sampel yang diambil secara Quota Sampling.Pada penelitian ini menggunakan teknik analisis data yaitu analisis kuantitatif dan anlisis kualitatif.Sumber data penelitian ini adalah penarikan data primer yang mempergunakan kuisioner, dengan memberikan skor pada jawaban responden. Pemberian skor ini akan menggunakan skala Likert. Hasil tabulasi jawaban responden selanjutnya di analisis dengan menggunakan indeks kepuasan wajib pajak dan analisis tingkat kepentingan kinerja (importance-performance analysis).Analisis kualitatif adalah 
analisis yang digunakan untuk melengkapi analisis kuantitatif yaitu dengan membuat uraian dari hasil penelitian dan menyajikan hasil penelitian tersebut dalam bentuk yang baik sehingga mendapatkan gambaran tentang hasil penelitian.

\section{HASIL DAN PEMBAHASAN} AnalisisIndek Kepuasan Wajib Pajak

Dalam menentukan katagori indek kepuasan wajib pajak maka harus dicari kepusan maksimum dan minimum untuk menentukan katagori kepuasan wajib pajak:

Skor indeks kepuasan maksimum adalah :
$100 \times 20 \times 5\{(5 \times 20)-(1 \times 20)\}$

$10.000 \times(100-20)$

$10.000 \times(80)=800.000$

Sekor kepuasan indeks minimum adalah :

$100 \times 20 \times 5\{(1 \times 20)-(5 \times 20)\}$

$10.000 \times(20-100)$

$10.000 \times(-80)=-800.000$

Dengan demikian rentang skor kepuasan wajib pajak adalah 800.000 - $(-800.000)=1.600 .000$. oleh karena tingkat kepusan diklarifikasikan menjadi 5 (lima), maka interval skor untuk setiap klasifikasi adalah $1.600 .000: 5=320.000$.

Jadi penentuan katagori indeks kepusan wajib pajak adalah

\begin{tabular}{ll}
\hline Total Skor & Klasifikasi \\
\hline$-800.000 \mathrm{~s} / \mathrm{d}-480.000$ & Sangat Tidak Puas \\
$-480.000 \mathrm{~s} / \mathrm{d}-160.000$ & Tidak Puas \\
$-160.000 \mathrm{~s} / \mathrm{d} 160.000$ & Kurang Puas \\
$160.000 \mathrm{~s} / \mathrm{d} 480.000$ & Puas \\
$480.000 \mathrm{~s} / \mathrm{d} 800.000$ & Sangat Puas \\
\hline
\end{tabular}

Berdasarkan pengukuran indeks kepuasan total menggunakan rumus skor kualitas jasa adalah (Fandy

Tjiptono,2001 : 100) :

Skor kulalitas jasa $=$ Skor derajat kepentingan $\mathrm{x}$ (Skor kinerja - Skor harapan $)$

Dimana :

$$
\begin{aligned}
& \text { Skor derajat kepentingan } \\
& =1 \text { (Importance })
\end{aligned}
$$

Sebagaimana terlihat pada ketiga tabel diatas maka diperoleh hasil sebagai berikut :
Skor Kinerja

$=\mathrm{P}($ Perfomance $)$

Skor Harapan

$=\mathrm{E}($ Expectation $)$ 


$$
\begin{array}{lll}
\begin{array}{l}
\text { Skor kualitas jasa } \\
\left(\sum P-\sum E\right)
\end{array} & =\sum I_{\mathrm{x}} & \\
& =8517 & \begin{array}{l}
\text { Jadi indeks kepuasan wajib pajak } \\
\text { pada kantor Pelayanan Pajak Pratama }
\end{array} \\
\mathrm{x}(7931-7855) & = & \begin{array}{l}
\text { Gianyar (KPP Gianyar) sebesar } \\
\text { 647.292 dimana point terletak antara } \\
\text { 480.000 sampai dengan 800.000 yang }
\end{array} \\
8.517 .(76) & \text { artinya sangat puas. }
\end{array}
$$

\begin{tabular}{|c|c|c|c|c|c|}
\hline Atribut-atribut & $\begin{array}{c}\text { Skor } \\
\text { penilai } \\
\text { an kinerja }\end{array}$ & $\begin{array}{c}\text { Skor } \\
\text { penilaian } \\
\text { kepenti } \\
\text { Ngan } \\
\end{array}$ & $\overline{\mathbf{X}}$ & $\overline{\mathbf{Y}}$ & $\begin{array}{c}\text { Tingkat } \\
\text { kesesuaian } \\
(\%)\end{array}$ \\
\hline $\begin{array}{l}\text { Bukti Langsung (Tangible) } \\
\text { 1) Kantor Pelayanan Pajak Pratama Gianyar megah. } \\
\text { 2) Tersedia ruang tunggu yang nyaman. } \\
\text { 3) Tersedia tempat parkir yang memadai. } \\
\text { 4) Petugas rapi dalam berpenampilan } \\
\end{array}$ & $\begin{array}{l}426 \\
415 \\
405 \\
419 \\
\end{array}$ & $\begin{array}{l}402 \\
422 \\
434 \\
404 \\
\end{array}$ & $\begin{array}{l}4,26 \\
4,15 \\
4,05 \\
4,19 \\
\end{array}$ & $\begin{array}{l}4,02 \\
4,22 \\
4,34 \\
4,04 \\
\end{array}$ & $\begin{array}{c}105,97 \\
98,34 \\
93,32 \\
103,71 \\
\end{array}$ \\
\hline $\begin{array}{l}\text { Keandalan (Reability) } \\
\text { 1) Petugas handal dalam menjalankan tugas sesuai harapan } \\
\text { yang diinginkan wajib pajak. } \\
\text { 2) Petugas mampu dan handal dalam memberikan pelayanan } \\
\text { 3) Respon petugas yang cepat terhadap pertanyaan dan } \\
\text { keluhan wajib pajak sudah sesuai harapan. } \\
\text { 4) Petugas sangat ramah dalam menanggapi pertanyaan wajib } \\
\text { pajak }\end{array}$ & $\begin{array}{l}415 \\
418 \\
424 \\
405\end{array}$ & $\begin{array}{r}416 \\
430 \\
429 \\
436\end{array}$ & $\begin{array}{l}4,15 \\
4,18 \\
4,24 \\
4,05\end{array}$ & $\begin{array}{l}4,16 \\
4,30 \\
4,29 \\
4,36\end{array}$ & $\begin{array}{l}99,76 \\
97,21 \\
98,83 \\
92,89\end{array}$ \\
\hline $\begin{array}{l}\text { Daya tanggap (Responsiveness) } \\
\text { 1) Petugas sigap dalam melayani wajib pajak } \\
\text { 2) Petugas tanggap dalam memberikan informasi } \\
\text { 3) Sikap petugas peduli dalam menangani keluhan diluar jam } \\
\text { kantor. } \\
\text { 4) Petugas bersedia menjawab pertanyaan wajib pajak. }\end{array}$ & $\begin{array}{l}424 \\
428 \\
413 \\
421 \\
\end{array}$ & $\begin{array}{l}433 \\
422 \\
430 \\
442 \\
\end{array}$ & $\begin{array}{l}4,24 \\
4,28 \\
4,13 \\
4,21 \\
\end{array}$ & $\begin{array}{l}4,33 \\
4,22 \\
4,30 \\
4,42 \\
\end{array}$ & $\begin{array}{l}97,92 \\
101,42 \\
96,05 \\
95,25\end{array}$ \\
\hline $\begin{array}{l}\text { Jaminan (Asurance) } \\
\text { 1) Petugas mampu berkomunikasi secara efektif. } \\
\text { 2) Petugas menjaga kerahasiaan data wajib pajak. } \\
\text { 3) Petugas ramah dalam memberikan pelayanan. } \\
\text { 4) Sikap professional petugas melaksanakan tugas. }\end{array}$ & $\begin{array}{l}427 \\
422 \\
395 \\
425 \\
\end{array}$ & $\begin{array}{l}427 \\
436 \\
435 \\
428 \\
\end{array}$ & $\begin{array}{l}4,27 \\
4,22 \\
3,95 \\
4,25 \\
\end{array}$ & $\begin{array}{l}4,27 \\
4,36 \\
4,35 \\
4,28 \\
\end{array}$ & $\begin{array}{c}100 \\
96,79 \\
90,80 \\
99,30\end{array}$ \\
\hline $\begin{array}{l}\text { Empati (Empathy) } \\
\text { 1) Instansi memperhatikan kesulitan yang dihadapi wajib }\end{array}$ & 413 & 431 & 4,13 & 4,31 & 95,82 \\
\hline $\begin{array}{l}\text { 2) Perhatianpetugas terhadap keluhan dari wajib pajak } \\
\text { 3) Petugas berusaha memberikan pelayanan terbaik. } \\
\text { 4) Petugas memberikan waktu untuk menyelesaikan masalah }\end{array}$ & $\begin{array}{l}412 \\
422 \\
418\end{array}$ & $\begin{array}{l}416 \\
427 \\
417 \\
\end{array}$ & $\begin{array}{l}4,12 \\
4,22 \\
4,18\end{array}$ & $\begin{array}{l}4,16 \\
4,27 \\
4,17\end{array}$ & $\begin{array}{l}99,04 \\
98,83 \\
100,24\end{array}$ \\
\hline Total & & & 83,45 & 85,17 & \\
\hline
\end{tabular}

\subsection{2}

Tabel : 5.5 Perhitungan rata-rata nilai kualitas pelayanan / kinerja dan tingkat kepentingan dari atribut-atribut yang mempengaruhi tingkat kepuasan wajib pajak.

Sumber: hasil data diolah tahun 2018 
f. Tingkat kepentingan dan

kinerja yang mempengaruhi

kepuasan masyarakat.

1. Perhitungan rata - rata dari rata - rata skor kinerja pelaksanaan seluruh atribut yang mempengaruhi kepusan wajib pajak

$$
\begin{aligned}
\overline{\bar{Y}} & =\frac{\sum_{i-1}^{n} \bar{y}}{k} \\
\overline{\mathrm{Y}} & =\frac{85,17}{20} \\
& =4,26
\end{aligned}
$$

$$
\begin{aligned}
\bar{X} & =\frac{\sum_{i=1}^{n} \bar{X}}{k} \\
\overline{\bar{X}} & =\frac{83,45}{20} \\
& =4,17
\end{aligned}
$$

2. Perhitungan rata - rata skor kepentingan pelaksanaan seuruh atribut yang mempengaruhi kepuasan wajib pajak 
Gambar 5.1 Diagram Kartesius

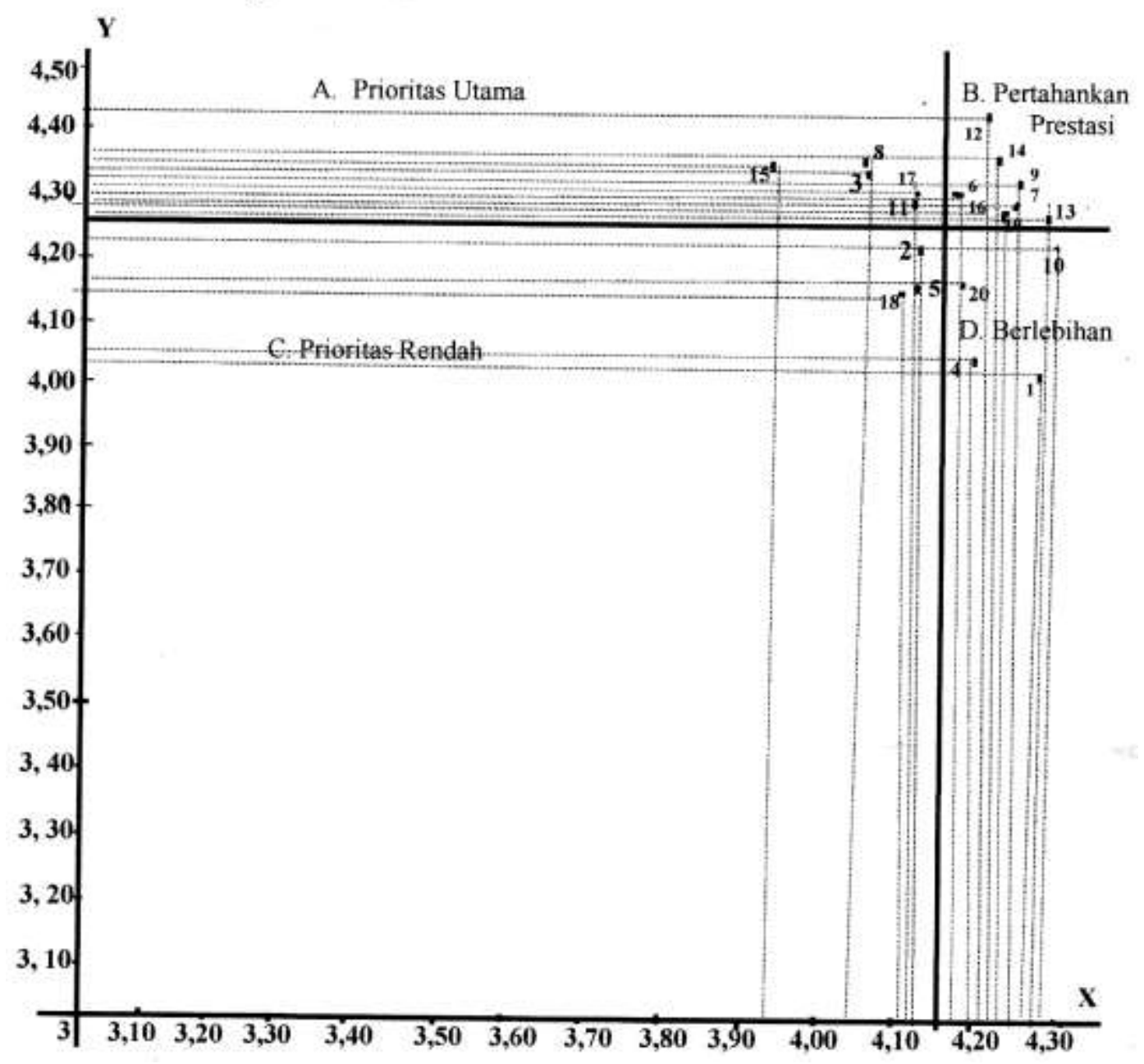

Berdasarkan gambar diagaram kartesius di atas letak dari faktor atau atribut yang mempengaruhi kepuasan wajib pajak kantor Pelayanan Pajak Pratama Gianyar terbagi menjadi 4 (empat) bagian. Ada pun interaksi diagram kartesius tersebut dapat dijelaskan sebagai berikut :

1. Kuadran A

Faktor
menempati kuadran ini
menujukan bahwa atribut-
atribut inilah yang di nilai
sangat penting oleh wajib
pajak namun tingkat

pelaksanaanya belum memuaskan. Atribut yang berada dalam kuadran ini adalah :
a. Atribut No. 3 :
Tersedia tempat parkir yang memadai.
b. Atribut No. 8
:Petugas sangat ramah dalam menanggapi pertanyaan wajib pajak
c. Atribut No. 11 : Sikap petugas peduli dalam menangani keluhan diluar jam kantor.


d. Atribut No. 15 :

Petugas ramah dalam memberikan pelayanan.

e. Atribut No. 17 : Instansi memperhatikan kesulitan yang dihadapi wajib pajak.

2. Kuadran B

Untuk atribut yang berada dalam kuadran ini menujukan bahwa jasa yang diberikan oleh Pegawai kantor Pelayanan Pajak Pratama Gianyar telah berhasil di laksanakan, untuk itu perlu dipertahankan. Atribut yang berada dalam kuadran ini adalah :
Petugas mampu dan
handal dalam
memberikan pelayanan
a. Atribut No 6 :
b. Atribut No. 7 :
Respon petugas yang
cepat terhadap
pertanyaan dan keluhan
wajib pajak sudah sesuai
harapan.
c. Atribut No. 9 :
Petugas sigap dalam melayani wajib pajak
d. Atribut No. 12 :
Petugas bersedia menjawab pertanyaan wajib pajak
e. Atribut No. 13 :
Petugas mampu
berkomunikasi secara efektif
f. Atribut No. 14 :
Petugas menjaga
kerahasiaan data wajib
pajak
g. Atribut No. 16 : Sikap professional petugas melaksanakan tugas.
h. Atribut No. 19 :
Petugas berusaha memberikan pelayanan terbaik.

3. Kuadran C

Menujukan atributatribut yang kurang penting dan pelaksanaanya bisa-bisa saja. Atribut yang berada dalam kuadran ini adalah :
a. Atribut No. 2 :
Tersedia ruang tunggu yang nyaman
b. Atribut No. 5 :
Petugas handal dalam menjalankan tugas sesuai harapan yang diinginkan wajib pajak
c. Atribut No. 18 :
Perhatian petugas terhadap keluhan dari wajibpajak.

4. Kuadran D

Atribut yang berada dalam ini menujukan bahwa nasabah menganggap pelaksanaanya berlebihan. Atribut ini kurang terlalu penting bagi masyarakat akan tetapi pelaksanaannya sudah dapat memuaskan masyarakat. Atribut yang berada dalam kuadran ini adalah :
a. Atribut No. 1 :
Kantor Pelayanan Pajak Pratama Gianyar megah
b. Atribut No. 4 :Petugas rapi dalam berpenampilan
c. Atribut No. 10 :
Petugas tanggap dalam memberikan informasi
d. Atribut No. 20 :
Petugas memberikan


waktu untuk

menyelesaikan masalah

Untuk menentukan faktor-

faktor yang perlu mendapatkan prioritas dari perusahaan dalam melakukan pembenahan data dilakukan dengan cara mengurutkan tingkat kesesuaian yang di peroleh.

Faktor yang memiliki tingkat kesesuaian yang terendah adalah faktor perlu mendapat prioritas utama. Semakin tinggi tingkat kesesuaian suaktu faktor, maka faktor tersebut mendapat prioritas yang semakin rendah. Tingkat kesesuaian ini dapat dilihat pada tabel berikut:

Tabel 5.6 Tingkat kesesuaian dan faktor-faktor yang mempengaruhi tingkat kepuasan wajib pajak pada kantor Pelayanan Pajak Pratama Gianyar (KPP Gianyar)

\begin{tabular}{|c|l|c|c|}
\hline No & \multicolumn{1}{|c|}{ Faktor-faktor } & $\begin{array}{c}\text { Tingkat kesesuaian } \\
(\%)\end{array}$ & $\begin{array}{c}\text { Priorita } \\
\text { s }\end{array}$ \\
\hline 1 & Kantor Pelayanan Pajak Pratama Gianyar sangat megah. & 105,97 & XX \\
\hline 2 & Tersedia ruang tunggu yang nyaman & 98,34 & X \\
\hline 3 & Tersedia tempat parkir yang memadai & 93,32 & III \\
\hline 4 & Petugas rapi dalam berpenampilan. & 103,71 & XIX \\
\hline 5 & $\begin{array}{l}\text { Petugas handal dalam menjalankan tugas sesuai harapan yang } \\
\text { diinginkan wajib pajak. }\end{array}$ & 99,76 & XV \\
\hline 6 & Petugas mampu dan handal memberikan pelayanan & 97,21 & VIII \\
\hline 7 & $\begin{array}{l}\text { Respon petugas yang cepat terhadap pertanyaan dan keluhan wajib } \\
\text { pajak sudah sesuai harapan. }\end{array}$ & 98,83 & XI \\
\hline 8 & Petugas ramah menanggapi pertanyaan wajib pajak. & 92,89 & II \\
\hline 9 & Petugas sigap melayani wajib pajak pada KPP Gianyar & 97,92 & IX \\
\hline 10 & Petugas tanggap dalam memberikan informasi yang jelas & 101,42 & XVIII \\
\hline 11 & Sikap petugas peduli menangani keluhan diluar jam kantor. & 96,05 & VI \\
\hline 12 & Petugas bersedia menjawab pertanyaan wajib pajak & 95,25 & IV \\
\hline 13 & Petugas mampu berkomunikasi secara efektif. & 100 & XVI \\
\hline 14 & Petugas menjaga kerahasiaan data wajib pajak. & 96,79 & VII \\
\hline 15 & Petugas ramah dalam memberikan pelayanan. & 90,80 & I \\
\hline 16 & Sikap professional petugas dalam melaksanakan tugas. & 99,30 & XIV \\
\hline 17 & Instansi memperhatikan kesulitan yang dihadapi wajib pajak. & 95,82 & V \\
\hline 18 & Perhatian instansI terhadap setiap keluhan dari wajib pajak & 99,04 & XIII \\
\hline 19 & Petugas berusaha memberikan pelayanan yang terbaik. & 98,83 & XII \\
\hline 20 & Petugas memberikan waktu untuk menyelesaikan masalah. & 100,24 & XVII \\
\hline Sum & & & \\
\hline
\end{tabular}

Sumber : Hasil Data Diolah tahun 2018

Berdasarkan Tabel 5.6 Tingkat kesesuaian dan faktor-faktor yang mempengaruhi tingkat kepuasan masyarakat pada Kantor Pelayanan
Pajak Pratama Gianyar yang yang menjadi prioritas utama adalah Petugas ramah dalam memberikan pelayanan dengan tingkat kesesuaian 
90,80 \% ( I ), sedangkan yang menjadi Prioritas terakhir adalah Kantor Pelayanan Pajak Pratama Gianyar sangat megah dengan tingkat kesesuaian105,97\% (XX).

\section{SIMPULAN}

Dari pembahasan mengenai tingkat kepuasan wajib pajak terhadap kualitas pelayanan yang diberikan oleh pegawai Kantor Pelayanan Pajak Pratama Gianyar maka dapat disimpulkan sebagai berikut :

Secara umum kualitas Pelayanan KPP Gianyar sudah baik, hal tersebut dapat dilihat dari indeks kepuasan wp. Berdasarkan perhitungan indeks kepuasan dengan menggunakan rumus indeks kepuasan masyarakat pada Kantor Pelayanan Pajak Pratama Gianyar sebesar 647.292 dimana point terletak antara 480.000 sampai dengan 800.000 yang artinya sangat puas.Berdasarkan teknik analisis tingkat kepentingan dengan tingkat kinerja atau pelaksanaannya dari 100 responden yang diteliti maka dapat dinyatakan bahwa faktor-faktor atau atribut-atribut yang dianggap penting dan dapat memuaskan wajib pajak KPP Gianyar terletak pada kuandran A yaitu : Teknik analisis tingkat kepentingan dengan tingkat kinerja atau pelaksanaan (Importance Performance Analysis) dari 100 responden yang diteliti, maka dapat dinyatakan bahwa faktor-faktor atau atribut-atribut yang mempengaruhi kepuasan konsumen yang penanganannya perlu diprioritaskan adalah atribut no. 3 yaitu tersedia tempat parkir yang memadai, atribut no. 8 yaitu petugas sangat ramah dalam menanggapi pertanyaan wajib pajak, atribut no. 11 yaitu sikap petugas peduli dalam menangani keluhan diluar jam kantor, atribut no. 15 yaitu petugas ramah dalam memberikan pelayanan dan atribut no. 17 yaitu instansi memperhatikan kesulitan yang dihadapi wajib pajak, karena keberadaan faktor inilah yang dinilai sangat penting oleh konsumen, sedangkan tingkat pelaksanaannya masih belum memuaskan.

\section{SARAN}

Berdasarkan simpulan diatas, maka disarankan bahwa :

Pegawai Kantor Pelayanan Pajak Pratama Gianyar agar melakukan peningkatan kinerja terutama yang pelaksanaanya belum dapat memuaskan wajib pajak; seperti memperhatikan kesulitan yang dihadapi wajib pajak, sikap petugas peduli dalam menangani keluhan diluar jam kantor, keramahan petugas dalam menanggapi pertanyaan wajib pajak dan keramahan petugas dalam memberikan pelayanan. Hal tersebut dapat diperbaiki dengan cara petugas Kantor Pelayanan Pajak Pratama Gianyar menerapkan 5S ( Senyum, Salam, Sapa, Sopan dan Santun ), memahami perasaan wajib pajak dengan cara memberikan perhatian serta menjaga volume suara namun tetap dapat didengar oleh wajib pajak. Selain itu perlu juga mempertahankan kinerja yang dalam pelaksanaannya sudah dianggap baik oleh wajib pajak ; seperti Petugas mampu dan handal dalam memberikan pelayanan, Respon petugas yang cepat terhadap pertanyaan dan keluhan wajib pajak, Petugas sigap dalam melayani wajib pajak, Petugas bersedia menjawab pertanyaan wajib pajak, Petugas mampu berkomunikasi secara efektif, Petugas menjaga kerahasiaan data 
wajib pajak, Sikap professional petugas melaksanakan tugas dan Petugas berusaha memberikan pelayanan terbaik.

Kepada Kantor Pelayanan Pajak Pratama Gianyar diharapkan dapat

\section{DAFTAR PUSTAKA}

Andriani, P.J.A. 1991. Pengantar Ilmu Hukum Pajak. Diterjemahkan oleh Brotodihardjo, R. Santoso. Jakarta : PT. Gramedia. http://www.pajak.go.id/

Kotler, Philip. 2007. Manajemen Pemasaran. Edisi Mellenium. PT. Prenhallindo, Jakarta.

Kotler, Philip dan Kevin Kaller. 2008. Manajemen Pemasaran Jilid 1. Jakarta : Erlangga.

Kotler, Philip. 1994. Manajemen Pemasaran: Analisis,

Perencanaan, Implementasi dan Pengendalian. Penerbit Salemba Empat.

Lopiyoadi Rambat 2001. Manajemen

Pemasaran Jasa. Salemba empat. Jakarta.

Margono. 2004. Metodologi Penelitian Pendidikan. Jakarta : Rineka Cipta.

Meutia Dewi (2016). Pengaruh Kualitas Pelayanan Terhadap Kepuasan Pasien Pengguna BPJS pada Rumah Sakit Rehabilitasi Medik Kabupaten Aceh Timur.

Sartika Moha., Sjendry Loindong (2016). Analisis Kualitas Pelayanan dan fasilitas Terhadap Kepuasan Konsumen Pada Hotel Yuta di Kota Manado.

Silvia Nila Krisnawati (2016). Analisis Kualitas Pelayanan memberikan kesempatan kepada pegawainya untuk mengikuti pelatihan-pelatihan yang berkaitan dengan kegiatan kantor pajak, khususnya yang berkaitan dengan kualitas pelayanan dan kualitas secara menyeluruh.

$$
\begin{aligned}
& \text { Terhadap Kepuasan } \\
& \text { Pelanggan SPBU No. } \\
& \text { 64.751.15 Samarinda. }
\end{aligned}
$$

Soemitra, Rochmat. 1990. Dasardasar Hukum Pajak dan Pajak Pendapatan. Jakarta : PT. Eresco Bandung.

Sugiyono. 2001. Teknik Sampling. Gramedia Pustaka Utama, Jakarta.

Sugiyono. 2012. Metode Penelitian Kuantitatif, Kualitatif dan $R \& D$. Bandung: Alfabeta.

Supranto. (2001). Pengukuran Tingkat Kepuasan Pelanggan Untuk Menaikkan Pangsa Pasar. Jakarta: Rineka Cipta

Tjiptono, Fandy. 2008. Manajemen Jasa. Yogyakarta : Andi Offset.

Tjiptono, Fandy. 2007. Pemasaran Jasa. Bayumedia, Malang.

Tjiptono, Fandy. 2008. Strategi Pemasaran :Edisi 3. Yogyakarta : Andi Offset.

Tjiptono, Fandi. (2001). Kualitas jasa: Pengukuran, Keterbatasan dan Implikasi Manajerial, Majalah Manajemen Usahawan Indonesia. Jakarta.

Tse dan Wilton (1988). Kepuasan Pelanggan, jilid 2. Edisi ketiga. Klaten : PT. Indeks Kelompok Gramedia.

Waluyo dan Wirawan, B.Ilyas. 2002. Perpajakan Indonesia. Jakarta : Penerbit Salemba Empat. 
Analisis Kualitas Pelayanan Terhadap Kepuasan Wajib Pajak Pada Kantor Pelayanan

Pajak Pratama Gianyar (KPP Gianyar)

Zeithaml, V.a., A. Parasuraman, and L.L. Berry (1990), Delivering Quality Service. New York: The Free Press. 2007. Undang-Undang No 6

Tahun 1983 Tentang Ketentuan
Umum dan Tata cara Perpajakan sebagaimana telah diubah terakhir dengan Undang-Undang No 28 Tahun 2007. 